\title{
Relaciones entre Chile y Japón: un siglo de acercamiento
}

\author{
Roberto de Andraca Barbás
}

$1 \begin{aligned} & \text { l comenzar el siglo XIX, el Asia } \\ & \text { Oriental mostraba un generaliza- } \\ & \text { do agotamiento político, en parte }\end{aligned}$ social aunque no económico. Poderosos imperios como China e India padecían de lastimeras decadencias. Otras zonas menos notables seguían inmersas en un espeso piélago de tradiciones y usos milenarios. Justamente, su menor relieve hizo a tales áreas menos desafiantes y más flexibles como para absorber el impacto agresor. Con menor costo se sometieron o negociaron con el poder invasor. Fueron los reinos de los archipiélagos, entre ellos, Japón. Cómo se integró el imperio del Sol Naciente a tales sucesos permitirá comprender el comienzo de la relación entre Japón y la pequeña nación sudamericana que era Chile.

El proceso global aludido involucra dos temas principales: uno, la integridad histórica del Lejano Oriente. El otro, la marcha de Occidente con su dilatada civilización judeo-cristiana, racional, individualista y muchas veces intolerante en su avance triunfal. Ambas trayectorias se cruza- ron no precisamente en un clima de respeto por el universo de creencias mutuas. En el siglo XIX, y aun hoy eso seria mucho pedir. Más bien fue un encuentro de mundos en una atmósfera cargada de agresividad a causa de la carrera por la expansión económica. Europa vivía su más autocomplaciente momento; desbordando cultura, se sentía llamada a dar paz y bienestar a pueblos atrasados -si es que no eran tenidos por primitivos-. Derrame de modernidad compuesta por una combinación de elementos científicos y tecnológi$\cos$, transportados en un fluido ideológico y religioso denso, sumamente corrosivo por su capacidad disolvente de culturas antiguas de gran complejidad. Europa, entrenada en el ejercicio de la expansión tras culminar el crecimiento dentro de sus propias márgenes; entonces, rica en población dispuesta a inundar el orbe. Una Europa de ciudadanos que ya habían completado o tenían muy maduros sus procesos de transformación política y social. Europeos libres, iguales sujetos de derecho, miembros de bien constituidos Esta- 
dos modernos. Individuos que apreciaban el decidir sin tener que pedir consejo; aventureros como los bergantines, que desplegaban sus velámenes e iban como enormes gaviotas llevando mercancías de Calcuta a Liverpool, de Amberes a Yakarta. Hombres liberales, que sembraron de bancos y casas comerciales las orillas de los mares.

\section{El gigantesco desarrollo del capitalismo llevó una variedad de productos europeos a todo el mundo.}

El gigantesco desarrollo del capitalismo significó reinversiones en los procesos productivos haciendo crecer cada vez más las hilanderías de la cuenca del Ródano, o de Manchester; o mejorando la producción lechera de Holanda. En todo caso, llevó la infinita variedad de productos europeos a todo el mundo. Hubo hierro y carbón suficiente para tender ferrocarriles en cualquier parte del globo. Hasta el más pequeño maharajá del Rajastán pudo soñar con tener un tren que bufara por su comarca. Si los deseos eran rentables, habría más de una entidad financiera dispuesta a realizar la inversión. Todos ganaban. El mundo parecía rebosar felicidad, y ganancias. En Europa, el optimismo embriagó aun a los más sobrios. La revolución financiera y monetaria llevó a gastar sin medida. La confianza en un futuro promisorio hizo montar intrincadas maquinarias económicas, más sutiles que los ingenios a vapor. Las teorizaciones y juegos de intangibles hicieron a los modernos Estados nacionales incrementar sus gastos, a sabiendas de que las recaudaciones crecían con cada aduana y cada navio, en algún lugar del mar. Se fue configurando así una gran contradicción, que acumuló sospechas a la par que crecía el capital. Por un lado, el gran comercio y el movimiento de capitales requerían de un mundo con fronteras más flexibles; por otro, la competencia con no poca agresividad entre los Estados, resaltó las diferencias. Los antagonismos se hicieron espinosos y vinieron los conflictos. La ausencia de mecanismos de regulación desencadenó guerras comerciales y coloniales, que aumentaron tanto más crecía la urgencia por el dominio estratégico y la fortaleza industrial. La abundancia de armamento, que no era ya el resultado de la pericia de armeros ni tenía el romance de los forjadores de espadas, agravaba las controversias. Ser fuerte significaba producir acero, fabricar cañones y rifles de repetición. Y la rivalidad mezclada con el negocio de las armas llevó al desarrollo de una maquinaria militar de temer, que permitió por una parte la estabilidad interna de los Estados al respaldar con la fuerza sus nuevas constituciones. Pero, por otra, desencadenó un peligroso armamentismo. El episodio final de esta saga se desencadenó en el siglo XX, en dos atroces guerras mundiales.

El caso de nación completamente desarrollada, y en pleno despliegue de su energía, fue Gran Bretaña. Potencia industrial, marítima y comercial, su expansión por el mapa ha sido bien explicada y hasta relatada de manera épica. El imperio británico, con su imaginario victoriano tuvo sus émulos. Pero ningún otro logró el 
tamaño ni la influencia, ni la riqueza que capitalizó Londres aunque todos se vieron envueltos en el entramado de negocios, tensiones y roces. Todo sucedió en varias escalas, desde asuntos ínfimos -aumentados por circunstancias localesa verdaderos problemas regionales. Francia trasladó sus propias fronteras y rivalidades a África; Alemania, más por orgullo que necesidad, logró enclaves asiáticos y en Oceanía. Fue Rusia quizás el imperio que territorialmente más creció en millas cuadradas, hasta chocar en uno de sus bordes con los intereses de Japón. Mientras, en el remoto horizonte desde donde sale el sol para Japón, crecían los Estados Unidos de América. Tras expandirse hasta los bordes del Pacífico, hacia el sur a costa de México, y ganar influencia en Centroamérica y el Caribe, la Unión quiso el océano, y entonces fue otro agresor.

Como esos relatos que se pueden leer en el Nihon Shoki', un guerrero se honra al ser desafiado por un antagonista de tamaño mayor: Estados Unidos ya era grande cuando llegó con sus buques hasta la bahía de Yedo. Y si bien hacia 1850 le faltaba mucho para ser el gigante que sería en el siglo XX, ya era la nación de más rápido desarrollo del Occidente. Su enorme territorio era una cornucopia que prodigaba riqueza ilimitada; por lo mismo, era la meta para miríadas de inmigrantes. $Y$ como los Estados Unidos aún dependían de capital extranjero, la veloz expansión requirió horizontes holgados de crecimiento, suficientes para mantener el interés de los inversionistas. Para garantizar el máximo de espacio político y económico, la Unión aumentó año a año su poder, hasta superar a Gran Bretaña en indicadores tan vitales como lo es la producción de acero, o en una flota que asegurara el poder marítimo ${ }^{2}$. Al otro lado del Pacífico, los hijos del Sol también asumieron su destino. E1 comodoro Perry, y su amenaza de 1853 fue la chispa. La Casa del Loto y del Cerezo hacía tiempo esperaba una agresión, aunque no sabía cómo llegaría. No obstante que en lo fundamental la sociedad japonesa era fiel a sus principios, venía sufriendo un complejo cambio que en sí marcaba el fin del Período Tokugawa (1600-1868). Entre adaptaciones y ajustes dolorosos, Japón supo responder con dignidad, aunque eso le significó perder terreno. Bien sabe el guerrero que primero se ha de estudiar al enemigo, conocer sus debilidades; solo así se puede preparar una contundente victoria. Y Japón se dedicó a aprender.

\section{El territorio de los Estados Unidos \\ era una cornucopia que prodigaba riqueza ilimitada.}

Seki, Keigi, Folktales of Japan, Chicago, The University of Chicago Press, 1963.

2 Mahan, Alfred Thayer, La infliencia del Poder Naval en la Historia, 1890. Obra que tuvo tremenda gravitación en la política norteamericana y en el mundo entero. Mahan, comandante de la marina estadounidense, escribió y subrayó, que el dominio del mar es la base del poder y de la prosperidad de las naciones. Una nación que desee ampliar sus horizontes debe asegurarse una amplitud oceánica suficiente, para lo cual debe procurarse una armada poderosa, que opere sobre estrechos y posesiones estratégicas, y lograr poseer enclaves que permitan una red de control sobre el comercio y el abastecimiento de las riquezas. 
La sacramental unión del pueblo japonés con su archipiélago se contrapone y complementa a la unidad de los seres vivos-personas incluidas-con el espíritu divino, encarnado en el emperador. Lo que se haga sobre la tierra no altera la esencia y alianza fundamental entre el territorio y sus habitantes. Llegaron los hombres a las islas hace demasiado tiempo, tanto que en la misma tradición se olvidó. Y cada vez que otros se quisieron unir a la comunidad y trajeron sus aportes, se aceptó su ofrenda si a cambio los recién llegados aceptaban respetar estructuras y mandos. Así, en varias oleadas arribaron el pensamiento y la cultura desde China; la última vez, junto con el budismo y el arte de la escritura $^{3}$. Desde el Período Heian (7941185) y quizás antes, la cultura japonesa aprendió a recibir, procesar, modificar y crear algo nuevo con lo llegado desde otros horizontes. La hoja de una katana o espada japonesa, se hace con sucesivas capas de acero fusionadas con pacientes golpes, firmes y precisos: alegoría del modo de aprender japonés y mejorar lo recibido. No fue extraño que Japón encarnara uno de los más sorprendentes procesos de desarrollo del siglo XIX. Japón no pasó de país feudal, agrario y antiguo, a nación moderna e industriosa, apreciación que ignora la aguda finura y el temple de su espíritu. Japón hizo lo que ya sabía hacer: aprender-si es preciso con dolor. De ese modo absorbió todo lo que le ofreció el Occidente. Como dragón, regurgitó lo que no le servía, pero hizo suyo lo útil y decisivo. Hasta hoy hace lo mismo.

\section{Japón hizo suyo lo útil y decisivo que le ofrecía Occidente.}

La constitución política que proclamó el imperio Meizi se inspiró en modelos europeos. Mas en esencia era una estructura legal nueva que sostenía el mismo organismo que sufría una metamorfosis de adaptación a un ambiente más global que el estrecho archipiélago. Ya había sucedido mil años antes, cuando hubo japoneses estudiando en el Hanlín Yuan -la alta academia fundada bajo la dinastía Tang de China, e incluso algunos osados príncipes de Kyoto fueron hasta la India a estudiar en afamadas universidades budistas. Nada de extraño tuvo en el siglo XIX enviar a la flor de la juventud nipona a Londres, a Berlín, a París, a Viena, donde sea que estuviese el conocimiento. La grulla sabe cuando llega el verano y viaja a la Mongolia, mas deja el nido preparado para el posterior retorno a su abrigo, en Yamagushi ${ }^{4}$.

El imperio japonés siempre existió. Como la semilla del ciprés crece en una maceta para regocijo y paz de quien la protege; mas, basta llevar la semilla al monte y el árbol se extiende en toda su gloria. Ya no bastaban botes de pesca; fue necesario construir buques de hierro. $Y$ de las cabalgadas de samurais se evolu-

3 Pigeot, Jacqueline y Tschudin, Jean-Jacques, El Japón y sus épocas literarias, Fondo de Cultura Económica, 1986.

4 Conferencia y publicación de Carrasco Álvarez, Sergio, «Nalanda, Universidad Budista», Revista de Historia, $\mathrm{N}^{\circ}$ 1, Universidad Gabriela Mistral, 2004. 
cionó al formidable ejército, y más tarde a la aviación. $Y$ así como tres siglos antes Toyotomi Hideyoshi capturó Corea y logró dominar la Manchuria, no debería extrañar que en el siglo en que se habló de espacios mínimos y necesidades de expansión, Japón mirara con codicia a su alrededor. La victoria de 1895 sobre las fuerza chinas fue el preludio del imperio, ya presto a expresar su pleno potencial. Hay autores que opinan que la toma de Formosa abrió el apetito imperial. No es así. El ciprés siempre fue ciprés, y por entonces empezaba a expandirse a su tamaño natural.

\section{Para crecer, Japón no escatimó paciencia ni gastos.}

Cuando los japoneses desean algo, buscan siempre lo mejor. Hacia 1870, estaban decididos a crecer, y se inspiraron en lo mejor disponible. No escatimaron en paciencia ni gastos. La marina siguió a la británica. El ejército copió al prusiano que recién había probado su eficacia derrotando a los franceses. En 1875 había en Japón un número importante de asesores ingleses y de alemanes, cada grupo trabajando en lo suyo. Al otro lado del mar en tanto, se desataba la guerra entre Bolivia, Perú y Chile, que no obstante la lejanía, interesó a más de un militar japonés. En especial, causó admiración el combate naval del 21 de mayo, episodio escuetamente informado en la prensa de Tokio. Ante el titánico despliegue de heroísmo y el increíble sentido del cumplimiento del deber, se empezó a seguir el desempeño de la armada y de los ejércitos chilenos. Concluida la guerra vinieron las indagaciones por más detalles. La sorpresa fue mayor cuando Chile también decidió nivelar su marina con la inglesa y prusianizar el ejército. $Y$ considerando las correctas relaciones ya existentes, se comenzó una gentil cooperación, intercambio de experiencias y de instructores.

Japón tuvo muy pronto su propia guerra. Tras sus contundentes avances en China, debió resistir la presión de Rusia que lo obligó a devolver Puerto Arturo y Manchuria. Pero los rusos no cumplieron el compromiso mutuo. Aprovechando la revuelta de los Boxers, las tropas rusas ocuparon Manchuria, logrando además la concesión de Puerto Arturo para instalar su flota oriental. La posición rusa se transformó en amenaza sobre Corea, por entonces bajo dominio japonés. La notable ganancia estratégica no satisfizo a Rusia que quiso más. Actuando sobre el gobierno coreano -por lo demás deseoso este de librarse de la tutela japonesa-, lograron otra base naval, esta vez demasiado próxima a la costa japonesa. La escalada rusa fue vista como intrusión en un área que Japón consideró de alta sensibilidad. Moscú, hija de Bizancio, usó su diplomacia para quedarse con lo adquirido. Pero Tokio estaba fuerte y quería demostrarlo. Tras romper relaciones, Japón lanzó un fulminante ataque y hundió la mitad de la flota rusa anclada en Puerto Arturo. A las pocas horas, el ejército japonés desembarcó en Corea y tomó Manchuria. Siguieron las batallas y los rusos recibieron un atroz castigo. Lo que quedó de la flota rusa del Pacífico también fue destruida. La de- 
fensa rusa fue desesperada y valerosa, pero el ejército japonés era una marea imparable. Puerto Arturo cayó en febrero de 1905. En su rescate vino la colosal flota rusa del Báltico, trasladada en agotador viaje. Pero fue interceptada y aniquilada cerca de la isla de Tsushima por la armada japonesa al mando del almirante Togo. La vergonzosa derrota culminó de manera trágica y bastante japonesa: la revolución rusa y el comienzo del fin del zarismo, sapukku del imperio de Moscú.

\section{Tras lograr un lugar destacado en la política mundial le correspondía combinar la fuerza con la diplomacia.}

El imperio japonés se había ganado un lugar destacado en la alta política mundial. Paso siguiente era aprender a combinar la fuerza con la diplomacia. El poder expresado en ocupación territorial, el comercio y derechos preferenciales, las ganancias económicas hicieron prestigioso al régimen del Mikado. Al interior, Japón era un bloque de granito; hacia afue$\mathrm{ra}$, los compromisos adquiridos y el nuevo estilo de relacionarse eran ya irreversibles. Tenía el poder de golpear con dureza o presentarse exhibiendo magnanimidad. Sin embargo, toda esa ganancia se había logrado demasiado rápido. Otras potencias adquirieron en siglos lo que Tokio tuvo en cincuenta años. Mutatis mutandis, Japón no poseía colonias, construidas sistemáticamente hasta ser parte de su territorio nacional, ni tenía una flota que surcara los mares, ni disponía de una población tan numerosa como para que se dis- persara por el mundo. La emergente potencia japonesa era una fuerza militar, aunque también una población disciplinada, capaz de construir una asombrosa plataforma industrial. Todo el esfuerzo de desarrollo se orientaba de preferencia hacia la defensa. Y consciente de la importancia de seguir por ese camino, tenía que ampliar los horizontes productivos de manera de competir con sus iguales en el exclusivo club.

Al comenzar el siglo XX, para ser fuerte había que asegurarse el acceso a las materias primas, de modo de poder continuar el desarrollo industrial. Había que mantener una conveniente interacción con mercados en los cuales colocar los productos $y$, por cierto, lograr el predominio marítimo indispensable para proteger el propio litoral, proyectarse sobre zonas donde fluían los abastecimientos y en caso necesario actuar más allá. Toda una doctrina que compartieron y practicaron desde los grandes a los países jóvenes, como Chile. Para Japón, la tendencia que marcaba la época fue absorbida dentro de las corrientes neo-shintoístas que proclamaban el advenimiento de un super-Japón. En las varias formas que en el debate interno cobró la discusión de cuán grande debía ser Japón, hubo acuerdo en que era imprescindible el dominio de un amplio radio marítimo. Si para los romanos hubo un mare nostrum, para el imperio japonés el control del mar implicaba aspirar al pleno dominio del océano Índico, de la zona de pasos y estrechos en Malasia, y la región oriental del océano Pacífico. Ese debía ser el mare niponnicus.

Japón también tuvo sus empire 
builders. Esos han de buscarse entre los líderes que recuperaron el espíritu de las viejas comunidades, los círculos y las cofradías. Escuelas, politécnicos, universidades, la estructura misma de la marina y del ejército descansó sobre instituciones consuetudinarias como el wakamono nakama. Si el imperio número uno, Gran Bretaña, triplicó sus posesiones a lo largo del siglo XIX, Japón en proporción, logró más. Siendo no más que un grupo de islas, que se podrían asemejar en mucho a las británicas, tenía la desventaja de ser el último imperio en entrar a la competencia, el más pobre en recursos, pero con una población temperada en mil años de austeridades. Describir brevemente ese Japón, es el siguiente paso.

\section{Durante casi un siglo Japón creció a} una tasa promedio del $3 \%$.

La era Meizi tuvo sus dificultades iniciales. Sin embargo, conseguida la cohesión de fuerzas vino la organización del país y el proceso de cambio ya no se detuvo. Investigaciones en historia económica demuestran que desde esa época Japón creció y se mantuvo creciendo por casi un siglo a una tasa promedio de $3 \%{ }^{5}$. En el mismo período, solo Estados Unidos supera esa marca con un 4.6\% ${ }^{6}$. Bajo el amparo $M e i z i$, se pudo consolidar un Estado que impulsó un notable desarrollo de la inversión pública. Mejores puertos, ca- minos y ferrocarriles crearon las condiciones para el fomento del comercio y la expansión exportadora. Por otra parte, Japón tuvo un notable aumento del consumo, que se nota de manera evidente en el volumen de importaciones, que alcanzó su momento más alto durante la guerra con Rusia a causa del elevado gasto en pertrechos y equipos. Pero puede considerarse que desde 1900 Japón ya vivía de lleno una economía capitalista que alcanzó la plenitud en las décadas siguientes cuando, a través del dirigismo estatal, desarrolló las industrias pesada y química. Shinojara Miyojei, estudioso de la historia económica japonesa ${ }^{7}$ señala que hasta 1940, no obstante la fuerte inversión en plantas industriales y equipos, se siguió dependiendo de compras en el exterior. Solo desde la reconstrucción (1950) Japón atribuye más importancia a los inventarios, por lo que ha buscado otro tipo de relación con sus mercados abastecedores.

Cabe destacar que Japón no ha experimentado grandes crisis, ni fenómenos depresivos que hayan afectado al país. Se puede decir que desde la restauración Meizi, se ha desarrollado sin grandes sobresaltos. Más aún, lo que en otras partes pudo traer consigo una caída de la demanda y una recesión, en Japón produjo el efecto contrario. Las diversas guerras en que se ha visto involucrado, han sido estímulos a nuevas fases de desarrollo. Desde la restauración Meizi Japón ha tenido
Takajusa, Nakamura, Economia Japonesa, estructura y desarrollo, El Colegio de México, p. 19. Department of Commerce, Historical Statistics of the United States, 1976, en Takajusa, ibidem, p.20. Miyojei, Shinojara, El desarrollo de la economíajaponesa y los ciclos, Soobunsha, 1961. 
un comportamiento económico estable y un desarrollo sin grandes sobresaltos, fenómeno que conlleva otra característica: el aumento del capital y su relación con la expansión de la fuerza de trabajo. Como se dijo, la revolución industrial en Europa fue sustentada por la abundante mano de obra, que se reflejó en variados fenómenos sociales. Japón vivió un notable aumento de población, pero no en proporción al positivo proceso económico. Hacia 1878 , la población total japonesa era de aproximadamente 36 millones, en 1940 era de 71 millones. Ese $100 \%$ de aumento en menos de un siglo sucedió a la par de un crecimiento industrial gigantesco, que originó una diferencia permanente respecto de la curva de disponibilidad de mano de obra. Contradicción de grado mayor que se notó a largo plazo e hizo impacto en las políticas y en el pensamiento estratégico. Ante la imposibilidad de aumentar la población, unido a la innata aversión a aceptar inmigrantes, el país desarrolló una forma muy particular de expansión. Japón no buscó adquirir territorios; en cierta manera lo que hizo fue expandir su experiencia y niponizar el Asia ${ }^{8}$.

\section{El objetivo fue lograr autonomía y autosuficiencia.}

Tomando algunas ideas de Morita Yudzoo $0^{9}$ examinando documentos sobre evolución monetaria, se puede sostener que por más de un siglo Japón ha disfrutado de un incremento del capital y de un notable flujo de dinero. Y si bien el gobierno imperial tuvo la tendencia natural a la austeridad y al control monetario, la combinación de ambas fuerzas favoreció la expansión. Durante el siglo XIX, Japón fue exportador moderado de hilados de seda cruda, té y productos del mar. La transformación comenzada en la era Meizi se apoyó en exportaciones de productos de más calidad ${ }^{10}$. Hacia 1880 , Japón había logrado desarrollar una industria algodonera que tenía como objetivo la enorme población china, mientras que el mercado interno era la base consumidora. Comprador importante fue el ejército, que vistió y equipó a su personal con estándares europeos. Como ya se ha señalado, el objetivo fue la nivelación tecnológica y la sustitución de importaciones, hasta lograr

8 Varios analistas han querido ver en este proceso un dirigismo ideológico que llevó a formular una especie de «doctrina Monroe japonesa». Tal doctrina imperialista alcanzaría su máxima expresión y se habria llevado a la práctica cuando Japón declaró ser la única salvación para China y quien tiene el derecho a intervenir en cualquier conflicto en el Asia. Análisis demasiado estructurado. Creemos que los sucesos se fueron encadenando de manera tal que Japón llevó su concepto de seguridad demasiado lejos, pero que no hubo una política central ni misional, ni de expansión mantenida. Sin llegar a la idealización de Richard Storry, compartimos su enfoque de defensa del espiritu japonés, como lo expone en su obra Richard Storry en $A$ history of modern Japan, Middlesex, Inglaterra, Penguin Books, 1960.

9 Análisis del desarrollo de la población japonesa, Nihon Jyooronsha. Cfr. la obra de Mosk, Carl, Japanese Industrial History: Technology, Urbanization, and Economic Growth, M.E., Sharpe, Nueva York, Armonk 2001, pp. 76-77.

10 Takeshi, Toyoda, A history pre-meiji commerce in Japan, Tokyo, Japan Cultural Society 1969. 
autonomía y autosuficiencia. El sostén para tal poder era la mayúscula capacidad de exportar bienes que retornaran grandes volúmenes de divisas. Tradicionalmente habían sido la industria textil y los bienes de consumo masivo, que se orientaban hacia la población regional, por lo que Japón fue un fiero competidor de la industria inglesa. En la mentalidad japonesa, hasta la generación de 1950 , podría afirmarse que estuvo instalada la imagen de un Japón textil. El Japón que sale a conquistar mercados mundiales es un fenómeno reciente. Hace un siglo, Japón se limitaba a repetir lo que hacía Inglaterra que, por lo demás, era el referente obligado. En sí, Japón se asemejaba a la Inglaterra preindustrial. Por largo tiempo Japón se vio a sí mismo como productor de bienes de consumo para inundar China y Corea. Pero para ello debía ser militarmente fuerte y políticamente integrado. Para lograrlo, debía ser autosuficiente en todo.

Cuando tras el encierro de siglos Japón tomó contacto con el mundo, las potencias poseedores de poder military fuerza económica avanzaban arrolladoras sobre Asia. Japón sin tener aún interés expansionista debió decidir entre cambiar o ser aplastado. Debía ser rico y fuerte.
El gobierno Meizi sabía que tener ferrocarriles y ser capaces de fabricar buques de hierro tenía como principal meta lograr el poder militar para hacerse respetados. Apoyado en ese principio, habría que entender que la transformación japonesa tuvo una orientación defensiva pero no militarista ${ }^{11}$. En el siglo XII China fue invadida por Gengis Khan, que quiso continuar su expansión hasta Japón. Lo intentó su descendiente Kublai Khan, pero el viento divino -o kamikaze se tragó la flota mongol. La potencial amenaza impulsó una cadena de cambios que culminaron en la consagración del protectorado militar o shogunato ${ }^{12}$.

Para subsistir frente a la agresividad china, se desarrolló el Japón marcial .

Para subsistir enfrente a la agresiva China de los mongoles, se desarrolló el Japón marcial, románticamente reflejado en las leyendas y hasta en el cine moderno. El país de los samurais que suele distorsionar al otro Japón: el del arte, del pensamiento, y sobre todo de la benevolente paz. Algo semejante pasó en 1850 . O se

II El análisis de los gastos militares a comienzos del siglo XX arroja curiosos resultados. Japón es el caso de una industria militar que mueve una economía, siendo el motor y a la vez el sistema de regulación. La secuencia de políticas de cada secretaría de defensa es un panegírico de la construcción del país en función de la seguridad. Desde 1900 a 1930, los gastos militares fueron en ascenso, pero se manejaban según las necesidades de la inversión industrial. En cambio, a partir de 1950, la reducción y fijación del gasto en defensa en el 1\% del PIB liberó un enorme porcentaje para ser invertido en otras áreas. Interesante es la visión de Wakamiya, Yoshibumi, The postwar conservative view of Asia: how the political right has delayed Japan's coming to terms with its history of aggression in Asia, Tokio, LTCB International Library Foundation, 1999. Cf. con G.C. Allen, A short economic history of modern Japan 1867-1937.

12 Kond, Agustín, Japón: Evolución histórica de un pueblo hasta 1650, Editorial Nerea. 
entraba en igualdad de condiciones a la comunidad de naciones hegemónicas o se era una víctima más. Y la opción pasó por el desarrollo de una industria militar que a la larga envalentonó al Japón y lo llevó a construir su propio imperio. Expansión militar que jamás fue la etapa culminante de un capitalismo expansivo sino la creación de un anillo de seguridad.

\section{Cada cierto tiempo el mundo vive oleadas mesiánicas de alcance global.}

Con todo, Japón era una nación de tradición guerrera y su frecuente participación en guerras externas facilitó que aflorara el apetito territorial. Nada censurable por entonces y poca moralidad tenían Rusia o Francia al sugerir que Japón renunciara a sus pretensiones regionales. La concatenación de hechos llevó a que los sueños en un Nuevo Orden para el Asia Oriental se transformaran en pesadilla militarista y agresión imperial. Pero hay que cuidarse de examinar los hechos con ojo occidental. Japón no construyó su imperio con interés políticocomercial o para la explotación de zonas ocupadas y el gobierno de Tokio no brindó un manto de protección a las inversiones de los privados, como lo hicieron las potencias europeas. Para llegar al estado final de cosas, mucho fluyó bajo los puentes del mundo, del Asia y del Japón.
Cada cierto tiempo el mundo vive oleadas mesiánicas de alcance global. El estatismo lo practicaron por igual Stalin, Roosevelt y Hitler. En Japón, la era Taisho (1912-1926) culminó en un relajo dulzón y peligroso para los equilibrios políticos que facilitó el paso al totalitarismo. El drama se desató hacia 1920, tiempos de un Japón feliz que gozaba del auge económico gracias a su inserción en la economía global. La presencia japonesa en los enclaves de la zona Asia-Pacífico había reemplazado a Alemania. Y considerando la preparación germana del ejército japonés, asumió su reemplazo de modo pleno. La fortaleza de la estructura militar nipona fue influenciando y militarizando la sociedad, a la vez que consagró la idea de una economía industrial guiada por el Estado hacia el fortalecimiento de la nación. La idea del ser nacional o kokutai -la suma existencial absoluta del país, con su alma que es el Teno, el emperador divino-, fue aceptada universalmente, confundiéndose con la experiencia religiosa. El concepto kokutai ya se había usado para la reconstrucción imperial en el período $\mathrm{Meizi}$. La era Showa ${ }^{13}$, comenzada en 1926, utilizó con más énfasis que nunca los símbolos imperiales organizando una amplia máquina de propaganda para captar la adhesión de la población ${ }^{14}$. Se llamó a la «devota fidelidad» con reformas y medidas muy favorables para el sector agríco-

13 Hirohito, el emperador Showa, (1901-1989) reinó desde 1926 hasta 1989; su reinado fue el más largo del Japón contemporáneo (N. del A.).

14 Al respecto véase el "Comunicado de los Diez Principios Políticos del gabinete de Jamaguchi" y el comentario del periódico Asaji Shinbu de Tokio, del 09 de Julio de 1929, en Knauth, Lothar, «Gobierno Civil y Fuerza Militar en la Década de los Treinta», Política y Pensamiento Politico en Japón, 1926-1982, El Colegio de México, pp. 25-31. 
la, desde donde llegaban los jóvenes reclutas para el ejército ${ }^{15}$. Se benefició a la gran industria, sin importar de paso proteger a los monopolios y a la clase adinerada, mientras se buscó el equilibrio usando el salario industrial como sistema de bienestar y al ejército como mecanismo de movilidad social. Ese formidable Japón, colosal como el acorazado Yamato, que aunque fue lanzado al agua años después, su titánico tamaño y poder, oscura y pavorosa belleza, semejan al Japón listo para embestir al vecindario. Hacia el año 1929 , oscuras maquinaciones, intrigas y asesinatos, derrumbaron el gobierno civil de partidos y le abrieron la puerta al militarismo, en lo suyo y en sus objetivos, sumamente exitoso.

\section{Japón arremetió contra una China dividida y vacilante.}

Japón fue una mole poderosa, que arremetió contra China, dividida y vacilante en sus experimentos republicanos. Manipuló, apoyó y movilizó a la variedad de caudillos que enfrentaban al Kuomintang de Chiang Kai-shek ${ }^{16}$. Logró separar a Manchuria del otrora Celeste Imperio, y protegió el nacimiento del nuevo Estado de Manchukuo. Manchuria y Mongolia eran un bocado irresistible para un Japón que necesitaba mostrar hacia adentro y al exterior su poderío. La Declaración de nacimiento del Estado de Manchuria ${ }^{17}$ evidencia el afán de crear Estados vasallos sobre los cuales prevalecer, tal como quedó establecido en el Protocolo que firmaron el Primer Ministro de Manchukuo y el Embajador Plenipotenciario de Japón ${ }^{18}$. Los hechos se encadenaron unos con otros, y Japón fue sacando ventajas. Con ruidoso acto, se retiró de la Liga de las Naciones, acusando a la comunidad internacional de hacer poco o nada por la estabilidad del Asia oriental, dando a entender que era deber del Teno -el espíritu pacificador imperial-, intervenir y poner las cosas en orden. $\mathrm{El}$ estallido de la guerra total sino-japonesa, fue el marco adecuado para la declaración del Nuevo Orden en el Este de Asia que a juicio de Japón estaba llamado a crear y garantizar. Los hechos que siguen han sido atribuidos a unos pocos. Ha pasado tantas veces. Está en la naturaleza humana acusar y esconderse en la autoindulgencia anónima. Hideki Tojo (1884-1948) fue el artífice intelectual de la invasión de Manchuria. Arquetipo del militar duro, conductor hacia la lucha total; él y otros altos oficiales junto a la élite secreta nacionalista -la Toseiha-, creyeron en la Esfera de co-prosperidad del Asia que debería liderar Japón. La ascendente

is Knauth, L., op. cit., pp. 31-32.

16 Chiang o Jiang Kai-shek o Jiang Jieshi (1887-1975), sucedió a Sun Yat-sen en la dirección del Partido Nacionalista, y fue líder máximo de la República de China (R.O.C.) proclamada en Nanking en 1927. Tras la derrota de los nacionalistas frente a los comunistas en 1949 se refugió con su gobierno en la isla de Taiván.

17 Knauth, op. cit., p. 36-38.

18 Ibidem, p. 39. 
carrera de Tojo, lo llevó al Ministerio de la Guerra y en sí a dirigir las operaciones militares durante la Segunda Guerra Mundial. Tojo fue juzgado y condenado por un tribunal internacional, y fue ejecutado en 1948. Stalin purgó silenciosamente a millones de rusos, y murió tranquilamente en su cama; el Japón imperial despertó de su mal sueño, y al menos halló a tiempo a quien condenar.

\section{Japón vio en Chile una imagen parecida de sí mismo.}

Para concluir este artículo, y usando una expresión budista, proponemos que la amistad de Japón hacia Chile ha sido un apego. Japón, en su bondadosa ignorancia idealizó su visión de Chile. En su agonía antigua, y drama de modernización, vio en Chile una imagen parecida de sí mismo. En este caso, un país joven pero pujante, que conquistó y se expandió con justos títulos. Supo de Chile y lo definió según sus sentimientos, como un país liderado por un gobierno fuerte, soberano, que conducía a un pueblo aguerrido y a la vez piadoso. Impresionó profundamente en los sectores japoneses cultos el muy particular sentido del honor de los militares chilenos, el sentido del deber y de la lealtad. La reciprocidad como bien moral, es máxima joya en el budismo-shintoísmo. Querer la amistad de esta tierra lejana era inducir una mutua fortuna beneficiosa.
Para la naciente República de Chile, Asia no tuvo importancia. Para quienes tenían alguna información, Japón a lo más sonaba a isla exótica. Desde los inicios del siglo XIX, Chile no tuvo interés en aventuras políticas ni comerciales en esa dirección. La joven república, no obstante novedosas ideas en asuntos de administración y comercio, seguía en mucho anclada al pasado. Marcada por esa tendencia, la diplomacia chilena reconstruyó el tejido imperial español y buscó relacionarse con las repúblicas hermanas; o bien acometiendo proyectos audaces, buscó la relación con países europeos que eran vanguardia del progreso. Igual como sucedió en Asia y ya lo hemos planteado, la élite chilena estaba convencida de que el progreso se relacionaba con el desarrollo de la industria y del comercio, por lo que el esfuerzo diplomático se orientó a estrechar lazos con Londres, París, Viena, Madrid, y en el más extravagante de los casos, tal vez Estambul. Pero ¿Tokio? Eso habría sido un imaginativo atrevimiento.

Un juvenil espíritu liberal inspiraba a la dirigencia política y el sano aire de la libertad mantenía el pulso del país acelerado. En enclaves en que se concentraban minorías industriosas, como Valparaíso, comenzaban a levantarse talleres y bodegas: se abrían bancos, se concedían créditos. Entre 1850 y 1870, la exportación de metales reorientó el destino agrario hacia otro industrial y minero ${ }^{19}$. El ferrocarril fue recia espina dorsal para la 
pujante vida económica ${ }^{20}$ y las primeras factorias insinuaban las que serían zonas industriales ${ }^{21}$. El imperio británico y sus competidores europeos contagiaban a las noveles naciones a sumarse a la excitante revolución industrial. En Chile, el aroma del progreso se olía en los puertos, donde se hablaba, se vestía, se negociaba como ingleses. Desde la costa, la modernidad penetró como corriente húmeda, y empapó a todos los niveles dirigentes. La pujante burguesía minera, comercial y bancaria se sentó con la clase terrateniente y puso sobre la misma mesa sus ideas modernizadoras. Más allá de analizar el fenómeno del desarrollo del liberalismo decimonónico, sus clubes reformistas y temas de cambio político en Chile, nos interesa señalar que en ese justo contexto nació la osada idea de relacionarse con naciones lejanas, casi legendarias. Los primeros registros acerca de contactos entre Chile y Japón son del año 1860 , cuando el gobierno chileno, en su intento por intensificar su comercio exterior, contempló instalar consulados en puertos principales del Asia. Pero, para ser más exactos, en el fondo lo que se hacía era integrarse a la red imperial británica, o en su defecto, al de las demás potencias. Entablar relación comercial con Calcuta y Bombay, era entrar al circuito británico. Instalarse en Japón era conseguir una invitación al festín expansivo angloamericano.

\section{Instalarse en Japón era conseguir una invitación al festín expansivo norteamericano.}

Dos hechos de la década de 1870 muestran los avances en el acercamiento. El primero, cuando en 1875 Japón participó en la Feria Internacional de la Quinta Normal. Segundo, cuando en 1882 don Benjamín Vicuña Mackenna, abogado, historiador y hombre público, fue nombrado miembro de la Sociedad de Geografia de Tokio, indicando en su designación su mérito como modernizador de Santiago. Como se puede ver, eran los talentos que apreciaba Japón. Pero, la escasa relación no quería decir desinterés ${ }^{22}$. Como ya señalamos, para Japón el conflicto entre Chile y Perú-Bolivia, los combates en el mar y las hazañas fueron seguidos desde la distancia con máxima curiosidad ${ }^{23}$.

vocación minera del país, sitúa los parámetros adecuados en que nace y se desarrolla lo que sería la gran minería desde su cuna en Copiapó donde se formaron las nuevas élites y comenzó la modificación de la sociedad chilena, su reestructuración y soporte minero, como más o menos es hasta hoy. Alliende, María Piedad, Historia del Ferrocarril en Chile, Santiago, Goethe-Institut, 1993, da una mirada sucinta, amena y gráfica de las vías de ferrocarril, desde la primera lína de Caldera a Copiapó a los grandes trazados longitudinales y ramales transversales.

21 Collier, Simon, A History of Chile, 1808-2002, Nueva York, Cambridge University Press, 2004, pp. 85-86.

22 Dos noticias de pequeña gran relevancia: en 1867 tocó puertos chilenos un barco japonés que buscaba nuevas rutas comerciales. $Y$ en 1883 ancló en Valparaiso durante su visita oficial, el buque de instrucción japonés «Ryujo» (o «Ryuujoo») al mando del comandante Ito.

23 La importancia internacional de la Guerra entre Perú-Bolivia y Chile, queda bastante clara en la colección 
Hubo admiración hacia el empuje y coraje de los chilenos y respeto por un pueblo que había sido capaz de aumentar su territorio y hacer reconocer su legítima ganancia. Tan sensible tema era para Japón, de máxima importancia, y la lejana nación sudamericana resultaba un interesante ejemplo.

\section{Fue surgiendo una clara simpatía hacia Chile.}

Lamentablemente, hay poca información de la apertura del Consulado de Chile en Yokohama, el año $1890^{24}$. Alfredo Cocq Port fue su primer titular, y los informes y cartas se perdieron entre el tumulto de hechos de la guerra civil de 1891. Superada la triste turbulencia se retomaron los proyectos y se reimpulsaron las relaciones bilaterales. A Japón le interesaba sacarle partido a la amistad, en cuanto la armada deseaba adquirir el buque Esmeralda III, formidable fragata completamente de acero, probablemente la nave más moderna en ese momento al alcance de Tokio. El buque fue traspasado y rebautizado con el nombre de Itzumi ${ }^{25}$. El Itzumi no alcanzó a participar en las acciones del conflicto con China, de 1894-95, pero su sola proximidad ya fue causa disuasiva para la cómoda posición que Tokio tuvo en las negociaciones con Rusia y las potencias europeas.

La gentileza chilena al ceder tan emblemática adquisición -la Esmeralda-, y traspasarlo a Japón jamás fue olvidada. En la armada y en los círculos intelectuales fue surgiendo una clara simpatía hacia Chile. Los hechos siguientes aumentarian las posibilidades de encuentro. Tras la guerra con Rusia, en 1905, Japón emprende una marcada etapa de industrialización, a lo que se suma una holgada posición comercial en el Asia. Al otro lado del Pacífico, Chile vivía la dulzura del salitre, que permitió inversiones y expansión en todas las direcciones. La búsqueda de nuevos horizontes, los buenos recuerdos de recientes negocios, llevaron a que el 25 de septiembre de 1897 se suscribiese en Washington el Tratado de Amistad, Comercio y Navegación entre Chile y el Imperio del Japón. Se lee en su Capítulo I que: «Habrá sólida y perpetua paz y amistad entre la República de Chile y el Imperio del Japón». En los siguientes quince capítulos se establece la recíproca libertad de comercio y navegación, el libre desplazamiento de sus nacionales y el pleno derecho a realizar negocios, a comerciar; y se regula la acreditación de diplo-

de Informes Inéditos de Diplomáticos Extranjeros durante la Guerra del Pacifico, Santiago, Editorial Andrés Bello, 1980. Véase los informes del embajador de Alemania a su cancillería. Tokio reunió en Europa la información de los sucesos en el norte de Chile y causó especial impacto en Tokio la coincidencia de pareceres de las potencias, en el sentido de no intervenir por motivo alguno en el conflicto sudamericano. ¿Habrán sido estas observaciones un aprendizaje antes de las aventuras en Manchuria? La información consular de la época apenas dice que en 1875 tenían residencia en Chile dos súbditos japoneses.

25 Basili Esbry, Juan Hugo, «E1 Itzumi, su historia y reflotamiento», Revista de Marina, № 105/783, marzo-abril, 1988. 
máticos. Dos años más tarde, se profundizó e hizo más explícito el Tratado, acordando que «los ciudadanos, naves y productos de Chile en el Japón, y los súbditos, naves y productos de Japón en Chile, gozarán respectivamente de todos los favores, privilegios o inmunidades concedidas a ciudadanos o súbditos o a naves y productos de cualquiera otra nación.»»

\section{La balanza comercial favorable a Chile llevó a estudiar la posibilidad de adquirir bienes industriales.}

En 1899, se suscribió y añadió al Tratado un Protocolo Adicional. En nombre del emperador firmó el vizconde Aoki Sinzo, Ministro de Relaciones Exteriores de Japón, y por Chile suscribió el protocolo Carlos Morla Vicuña. Aparte de suscribir el acuerdo, Morla se preocupó de establecer los vínculos necesarios para introducir el salitre chileno ${ }^{26}$. Nada fácil hasta hoy colocar un artículo en el mercado japonés. Pero la misión Morla consiguió el apoyo del Banco Nacional del Japón, que dispuso del capital para las importaciones de nitrato. Comenzaba una era de creciente intercambio económico con el salitre como producto estrella, pero con una balanza comercial siempre favorable para el lado chileno. Entonces, para no inquietar tan promisoria relación, se encargó a las misiones chilenas estudiar posibilidades de reciprocidad, e informar de posibles adquisiciones de bienes industriales. Y comenzaron a sucederse los negocios, como la adquisición de locomotoras Tipo 70, que por provenir de Japón fueron llamadas Mikado ${ }^{27}$.

Chile y Japón se miraban y reconocían como países de respeto en el concierto internacional. Hay casos como los sucesos de México, de 1911, que prueban el excelente nivel de las relaciones bilaterales $^{28}$, que se traducía en negocios salitreros ${ }^{29}$. Hacia 1909 , las exportacio-

26 El problema del ingreso del salitre en Japón, en el trabajo de Jara, Mauricio, Chile y el imperio del Japón, 1897-1911: Los inicios de la expansión diplomática y salitrera en el Asia.

27 Las locomotoras Tipo 70 se usaron para trenes de carga, inicialmente entre Valparaíso y Santiago. Fueron fabricadas en Estados Unidos y se exportaron a Japón, pais que a su vez las compró a Ferrocarriles del Estado de Chile. Estas pesadas y poderosas locomotoras fueron acicate de una notable revolución tecnológica. Entre otras cosas, se debió adaptar el proyecto Puente Ferroviario sobre el río Mílleco, hoy declarado Monumento de la Ingeniería Mundial por la Sociedad Americana de Ingeniería. Se prefabricó como mecano en Francia y se transportó a Chile en grandes cajones; su montaje duró casi 20 meses y se inauguró en 1890 .

El caso de la protección ofrecida por las misiones diplomáticas de Chile y de Japón a Francisco Indalecio Madero, Presidente constitucional derrocado por el general Victoriano Huerta. Madero y miembros del gobierno fueron detenidos y se temió por sus vidas. Más los embajadores de Chile y de Japón se jugaron para salvar al Presidente, a los demás personeros y a sus familias. El ministro chileno consiguió salvoconductos y se ofreció como garante para la salida de los prisioneros, pero Francisco Madero fue ejecutado, e igual suerte corrió el vicepresidente Pino Suárez. La tragedia ajena unió a ambas naciones, Chile y Japón, al hacerse reconocimiento mutuo de los similares rectos e impecables principios de sus funcionarios. 
nes chilenas a Japón sumaban 3.3 millones de pesos, contra 0.37 millones de importaciones. Balanza desequilibrada y que no tendía a mejorar, no obstante los esfuerzos de las misiones diplomáticas en Tokio y Santiago ${ }^{30}$. Durante la primera Gran Guerra las exportaciones japonesas de seda y arroz a Europa cayeron de modo espectacular, lo que afectó a los agricultores japoneses que restringieron el consumo de fertilizantes. Era lógico esperar que los envíos de salitre se redujeran. Pero, una misión del Ministerio del Comercio de Japón llegó a Santiago con el fin de intensificar los lazos comerciales. La misión recorrió talleres y maestranzas, llevándose información para estudiar posibles negocios. Y la reciprocidad vino por donde no se esperaba. Ambos ejércitos vieron como interesante la cooperación en equipos y materiales. Es bastante conocida la visita a Japón del teniente coronel Lagreze, quien recorrió con toda libertad instalaciones y fábricas militares y evaluó el armamento producido en Japón con miras a la posible producción en Chile. Y hubo negocio, por mucho que la compra de materiales bélicos a Japón se explica por la escasez internacional de pertrechos y municiones a causa de la guerra de 1914. Japón, debido a su reciente beligerancia, se había impuesto mantener un alto grado de preparación militar y en consideración a todo lo expuesto, se hallaba en una etapa muy avanzada de sustitución de importaciones. Al desencadenarse los varios escenarios de la Gran Guerra, Japón estaba extraordinariamente preparado para defender su integridad imperial. Ante la escasez de alternativas, esto resultó interesante para Chile.

\section{El encuentro y el intercambio obedecían más a la necesidad que a una relación bien aprovechada.}

Por otra parte, el imperio había quedado $\sin$ proveedores de trigo, producto cada vez más consumido en la dieta japonesa, en circunstancias de que Chile vivía justo un auge de excedentes cerealeros. El problema del comercio salitrero pudo subsanarse, mediante las gestiones de la empresa Susuka, la más importante importadora de fertilizantes. Con todo, el encuentro y el intercambio obedecían más a la necesidad que a una relación bien

primera delegación consular de Japón a Chile a cargo del Ministro Plenipotenciario señor Yoki Hioki. Meses después, la compañía de navegación Toyo Kisen Kaisha inicia viajes regulares a Valparaíso. Ese mismo año de 1910 en que ya recalaban en el país naves mercantes japonesas, se desembarcaron las cajas en que venían obras de arte que se instalaron en la inauguración del Museo de Bellas Artes de Santiago. Dos años despúes, en 1912, abre sus puertas la casa comercial Senda y Cia., en Valparaíso. En 1913 lo hace la casa comercial Shimizu y El Nuevo Japón.

Algunos hitos interesantes, relatados en varias historias locales chilenas dicen que en 1902 visitó y se presentó en Valparaíso el conjunto teatral japonés «Compañía Imperial Fukushima». Años después, los titulares del diario El Mercurio, mencionan que el buque escuela «Baquedano» en retribución a previas visitas japonesas, viajara a Japón al mando del capitán de navío Luis Gómez Carreño. El viaje se repitió los años 1908 y 1911. 
aprovechada. Quizás se debió al grado de ignorancia de lo que era Japón, y al desconocimiento de la disciplina y eficiencia japonesas. La oportunidad de entablar una relación más intensa se dio en ese momento. Hubo alguna conciencia en las autoridades, pero faltó decisión política. Error que no podemos volver a cometer. Tal vez fue para mejor. Los años que siguen sumieron a Japón en una espiral violenta, con el desenlace bien conocido en la Segunda Guerra Mundial.

\section{A mediano plazo, la decadencia de la industria salitrera aceleró la transformación de la sociedad chilena.}

En los años treinta Chile vivió tiempos difíciles. La gran crisis mundial remeció la economía chilena. Las consecuencias de la gran crisis y la decadencia de la industria salitrera fueron explosivas en lo inmediato y a mediano plazo aceleraron la transformación de la sociedad chilena. Nuevas alianzas e idearios reflejaron la preocupación por la cosa social. Mientras, en el desarrollo económico el Estado desempeñó un papel fundamental. Por esa década, las relaciones con Japón descienden a un nivel elemental ${ }^{31}$. No retroceden, pero debido a que cada país seguía trayectorias tan opuestas, el resulta- do fue el alejamiento. Por otra parte, decreció el incentivo económico. Los precios de los productos chilenos descendieron y el esfuerzo por llegar a Japón no compensaba las magras ganancias. Fue mejor vender en el mismo vecindario. La balanza comercial, que históricamente fue favorable a Chile, ahora se movió hacia el lado japonés, lo que llevó a las autoridades chilenas a enfriar el entusiasmo con que se aplicaba el Tratado de 1897. Hacia 1930, el comercio con Japón representaba para Chile el $5 \%$ del intercambio. Al finalizar la década, había caído a un nivel ínfimo, apenas para justificar las siempre amigables relaciones.

Cuando se produjo el ataque a Pearl Harbor en diciembre de 1941, las relaciones bilaterales entre Chile y Japón eran mínimas aunque normales. Tras el ataque, el gobierno chileno condenó el acto, citando preceptos de legalidad y acuerdos internacionales existentes en la región de los hechos. La actitud de censura se hizo cuidando no insinuary mucho menos significar alineamiento de Chile con los Estados Unidos. Por el contrario, haciendo gala de la larga tradición de independencia en política exterior, la República de Chile se remitió a aplicar los tratados vigentes que hacían referencia a una agresión foránea hacia un miembro de la comunidad internaciona ${ }^{32}$.

El apoyo chileno al bloque aliado res-

31 Barros van Buren, Mario, La politica exterior de Chile durante el siglo XX, FT No 6, 1998, pp. 80-86. En el primer cuarto del siglo XX Chile sufrió una notable decadencia y vulnerabilidad exterior. El arrojo en emprender aventuras negociadoras mutó en un tímido interés por acuerdos con los países vecinos, intentó crear un círculo de amistad alrededor y participar activamente en las nuevas organizaciones multinacionales.

32 Barros van Buren, Mario, La Diplomacia Chilena en la Segunda Guerra Mundial, Santiago, Ediciones Arquén, 1998. En sus algo más de 400 páginas hace un análisis de la política del Estado chileno 
pondió a coyunturas internas y es lícito afirmar que el entusiasmo iba de tibio a frío. Nada había contra Japón. Fue la presión de Estados Unidos, la actitud solidaria hacia los países de la región, y la acción política de sectores de izquierda que llevaron a suspender las relaciones bilaterales el 20 de enero de $1943^{33}$. Al terminar la guerra y darse comienzo a la reconstrucción del Japón, se dieron las condiciones para restablecer el estatus diplomático perdido ${ }^{34}$. El acercamiento se concretó en San Francisco el 4 de septiembre de 1952, con motivo de la firma del Tratado de Paz entre Estados Unidos y Japón. Las relaciones en plenitud se 10graron el 7 de octubre de 1952, con la siguiente nota del Embajador de Chile en Washington a su par japonés en la misma ciudad: «En consideración al mutuo deseo de nuestros respectivos gobiernos de restablecer la normalidad de relaciones diplomáticas y consulares, aun antes que haya entrado en vigencia entre ellos el Tratado de Paz de 8 de septiembre de 1851 , tengo el honor de manifestar a Vues- tra Excelencia, en cumplimiento a instrucciones recibidas de mi gobierno, que el gobierno de Chile tendrá el mayor placer en recibir a los representantes diplomáticos y consulares del gobierno del Japón $\rangle^{35}$. Ambas embajadas estuvieron oficialmente constituidas en mayo de 1957. Entonces, fue embajador chileno en Tokio don Roberto Suárez Barros y representó a Japón en Santiago el señor embajador Rokuzo Yaguchio. A partir de ese momento, las relaciones han sido estables y consistentes $^{36}$. La presencia de Japón en Chile se intensificó en lo comercial y se relacionó con el respaldo de Estados Unidos hacia los países de América Latina a través de la Alianza para el Progreso. Fue importante la inversión en proyectos mineros de hierro y de cobre.

\section{Ante borrascas coyunturales, suele reaccionarse de manera vacilante.}

ante la situación de guerra y las gestiones diplomáticas que se emprendieron desde 1939 a 1945 . El autor distingue dos etapas, antes y después de la ruptura de relaciones con el Eje en 1943, dejando de manifiesto la posición de la Cancilleria chilena favorable a la neutralidad. Destaca la figura del canciller Ernesto Barros Jarpa, que abandonó el cargo cuando se hizo insostenible mantenerse al margen del conflicto debido a la gravitación de los Estados Unidos. La presión norteamericana llevó a Chile a declarar la guerra a Japón poco antes del término de la guerra, en cuanto se le exigía este paso para ingresar como miembro fundador a la Organización de las Naciones Unidas. Decreto $\mathrm{N}^{\circ} 182$.

34 La inserción de Japón en el concierto internacional fue lento. La nueva constitución de 1947 cambió la estructura sociopolítica y económica del país. Se eliminaron los zaibatsus o grandes propiedades agrícolas, se aseguraron los derechos laborales, se permitió formar sindicatos y se reconoció el derecho a huelga, se aseguró el derecho a reunión, de expresión y de religión.

35 En 1955 se aprueba el Tratado de Paz con el Japón, suscrito en San Francisco, Estados Unidos de América el 8 de Septiembre de 1951.

36 Barros Van Buren, Mario y Pinochet de la Barra, Oscar, Chile y Japón: un siglo de amistad 18971997. Santiago, Comisión Chilena de Celebración del Centenario de las Relaciones Chile-Japón, 1997. 


\section{Además del intercambio comercial}

\section{han aumentado la integración y la cooperación tecnológica.}

Conviene recordar aquí un hecho extraordinario y de tremenda significación. Comparada con la población japonesa en Chile otras colonias de residentes, era ínfima $^{37}$. En 1941, ante los evidentes vientos de guerra, esa pequeña comunidad quiso hacer pública su inquietud, mezclada con gratitud y manifestar su deseo de ser considerados parte de Chile, de su destino y de su pueblo. Y teniendo como pretexto la celebración de los cuatrocientos años de la fundación de Santiago, en un sorprendente acto, esos residentes gestionaron ante el gobierno de Tokio la confección y luego el obsequio de la gigantesca bandera chilena que hasta hoy flamea cada 18 de septiembre frente al Palacio de La Moneda. Hace pocos años, al cumplirse un siglo de relaciones diplomáticas, Chile replicó tan gentil y fraterna manifestación obsequiando una bandera japonesa que se izó en la bahía de Tokio ${ }^{38}$. Pero a veces sucede, que ante borras- cas coyunturales se reacciona de manera vacilante, y se olvidan promesas de amistad eterna. Meses más tarde, al suspenderse las relaciones diplomáticas y consulares con «las naciones del Eje», se aplicaron medidas restrictivas a los japoneses residentes. La sociedad japonesa, temiendo que pudiese llegarse a extremos, como había sucedido en otras partes, arrendó y organizó una hacienda colectiva para dar trabajo y socorro a las víctimas de las «lista negras». El tema hoy está olvidado. Nadie pidió disculpas, pero tampoco hubo resentimiento en los nikkei criollos. Por el contrario, quince años después, en 1960, cuando el sur de Chile fue arrasado por un feroz terremoto, el gobierno del Japón fue uno de los primeros países en enviar ayuda a la zona de Valdivia y la colonia residente una de las que más se movió para hacer llegar la ayuda $^{39}$. Los maremotos nos unen. Desde entonces se intercambia información y ambos países se han ido integrando a una red de alerta sobre eventos telúricos. Eso sucedió justamente durante la década de los años setenta. Japón tuvo una política de acercamiento y grandes empresas ja-

37 El estudio de Baldomero Estrada, Presencia Japonesa en la Región de Valparaiso, 1997, muestra la realidad japonesa en Chile. El Profesor Estrada, conocedor de la dinámica de las colonias italianas o alemanas, desarrolla el tema de la pequeña y decorosa colonia japonesa en la Quinta Región. Su situación en Santiago debió ser bastante semejante.

38 Fue para la conmemoración de un siglo de relaciones diplomáticas, que Chile, por iniciativa de este autor se propuso donar a Japón una bandera japonesa hecha de Linos de La Unión, de 10 por 7 metros, que fue transportada por el buque escuela Esmeralda y entregada, en solemne ceremonia, en el Parque Hasumi, en la bahía de Tokio y ante Sus Altezas Imperiales y el Presidente Eduardo Frei Ruiz-Tagle y formaciones de honor de ambas Fuerzas Armadas. El mástil, de 30 metros, con la bandera flameando, puede verse desde muy lejos.

39 La obra de Maria Teresa Ferrando Hanus, Al otro lado del Pacifico, japoneses en Chile, 1900-1960, publicada en 2004, es un muy documentado recuento de lo que ha sido el proceso de desarrollo de la población japonesa en nuestro país. 
ponesas buscaron asociarse a proyectos atractivos. La minería del hierro fue una de las receptoras favorecidas por el creciente interés ${ }^{40}$ además de las actividades pesqueras. La década de los ochenta vio crecer el intercambio, con un claro margen para Chile además de cooperación y apoyo tecnológico, a nuestro favor. El Acuerdo de Cooperación Técnica de $1978^{41}$ tuvo por consecuencia que en 1983 se estableciera en Santiago la Agencia de Cooperación Internacional del Japón (JICA), que ha beneficiado a varios centros de investigación y educación chilenos.

Los años recientes han sido favorables para el desarrollo de las relaciones bilaterales. Además del potente crecimiento en el intercambio comercial, han aumentado la integración y la cooperación tecnológica. En el ámbito de la cultura, ambos gobiernos se han preocupado de aumentar el conocimiento mutuo entre ambos pueblos. Japón nos ha regalado con su arte, literatura, danza, drama, cine, artesanía, y otras expresiones de la cultura. Chile se podría considerar favorecido por una seria amistad y trato preferencial. Japón es el primer comprador de productos chilenos, y el tercero en la procedencia de nuestras importaciones. La inversión directa crece cada año en la industria minera, en silvicultura y pesca. Las relaciones bilaterales con el Japón se hallan en un excelente momento, resultado de años de lealtad comercial, en un contexto de globalización que no ha diluido el compromiso bilateral. Porque la amistad no es un tema de mercado. Chile representa apenas un par de puntos porcentuales en el enorme volumen de negocios de Japón. Tampoco somos un país de inmigración japonesa ${ }^{42}$. La colonia residente apenas se nota. Hay en Chile menos de dos mil japoneses, casi todos ciudadanos chilenos, nikkeis descendientes de emigrantes llegados hace tiempo, a veces ni siquiera de Japón sino de países vecinos.

\section{Aunque Japón es la segunda economía del mundo y Chile un país pequeño, estamos unidos.}

¿Qué nos hace cercanos? ¿Cómo explicar la gentil lealtad japonesa hacia un país que ve la relación mutua a veces solo con el ojo de la conveniencia y de la ganancia a corto plazo? Quisiera decirlo con un ejemplo: hace unos diez años, estando en Tokio, cenaba en la casa de un matrimonio japonés. Y esa noche hablábamos de la lealtad, la fidelidad, y del amor. No era una conversación fácil, pues a pesar que nos conocíamos hacía años, en ese

Véase los anuarios y en especial las Memorias de CAP S.A.

Se promulga Acuerdo por el cual Japón suministrará Equipos de Educación Científica al Ministerio de Educación Pública, suscrito en Santiago el 6 de Junio de 1980.

2 Según datos recordados en anales de la minería, en 1907 arribaron trabajadores japoneses a la mina Koyahuashi, en Tarapacá. Pero, no hay antecedentes sobre su permanencia. Los datos oficiales del Censo Poblacional Chileno de ese mismo año contabilizó a 209 personas de origen japonés, distribuidas en nueve localidades del país. En 1920, el mismo censo contabilizó a 557 japoneses y los localizó en veinte lugares del Chile. Diez años después, el censo contó a 670 japoneses establecidos en Chile. 
tema entrábamos a comparar todo lo que éramos, nuestra formación desde los cimientos íntimos hasta la cotidianeidad o la causa que nos reunía. Para explicarme esa pareja cómo tras cuarenta años de casados habían conquistado el amor me hablaron así. «Nos conocimos casi el mismo día que contrajimos matrimonio. Era otra época, y la autoridad indiscutible de los padres hacía que esa y no otra, fuese la manera de hallar la mujer o el hombre que sería tu compañero para toda la vida. $Y$ los padres hacían la elección también con amor, por lo que no cabría la desobediencia, hija del miedo. Normalmente no se equivocaban. Y se sucedían los años jóvenes; entre juegos de pasión, cada cual buscando en el otro las necesidades de su propio yo. Con el paso de los años, se iba agotando el egoísmo y dando gradual paso a la entrega, a la generosidad, al desarrollo espiritual que tiene su mejor contexto en la pequeña y más ideal sociedad, que es nuestra idea japonesa de familia. Vimos crecer a nuestros hijos, y en el esfuerzo y el sacrificio por hacerlos personas de valer, nos fuimos uniendo y proyectando, hasta que les buscamos también marido o mujer. $Y$ se fueron. Todo estaba cumplido. Pero, quedaba más. Hace poco, al cumplir cuarenta años de matrimonio se reunió toda nuestra descendencia. $Y$, en un momento, estando sentados mirando el jardín donde jugaba el grupo de nietos, nos vimos en ellos. Vimos la expansión y derrame de toda nuestra exis- tencia. Esos niños, que jugaban inocentes de todo lo que había hacia atrás, eran el resultado de cuarenta años de unión. $Y$ por fin supimos que nos amábamos, y no sólo que lo sentíamos intensamente sino que habíamos materializado el amor». Nunca he oído una mejor definición del matrimonio.

Quisiera ver las relaciones de Chile y Japón como un largo noviazgo que ya entró a la edad de la madurez. Nos acercó el siglo XIX y sin hacer que el ejemplo matrimonial resulte demasiado textual, ambos contrayentes se cruzaron a pesar de su pasado infinitamente distinto e incomparable. Sin embargo, el destino los unió. Chile y Japón, fueron satisfaciendo necesidades puntuales. Hubo momentos de grata calidez, compañia, abrazos de formal amistad, seguidos de lejanías; hubo momentos de frialdad, y tibios reencuentros. Vino la madurez de la relación, y ha dado frutos. No digamos hijos, que en este caso, sería apelar a argumentos sentimentales, y mencionar a amigos de la Asociación Japonesa. Llegó el futuro, con proyectos enormes donde ha quedado demostrada la mutua confianza. Japón es la segunda economía del mundo; Chile es un país pequeño, pero estamos unidos. La amistad de más de cien años -estoy convencido- cruzó hace tiempo necesarias etapas de satisfacción de las conveniencias. Ahora trabajamos juntos, con generosidad, para las generaciones venideras. 